\title{
Hexaminolevulinate blue light cystoscopy (Hal) assisted transurethral resection of the bladder tumour vs white light transurethral resection of the bladder tumour in non-muscle invasive bladder cancer (NMIBC): A retrospective analysis
}

\author{
Marco Capece ${ }^{1}$, Lorenzo Spirito ${ }^{2}$, Roberto La Rocca ${ }^{2}$, Luigi Napolitano ${ }^{2}$, Roberto Buonopane ${ }^{1}$, \\ Sergio Di Meo ${ }^{1}$, Maurizio Sodo ${ }^{2}$, Umberto Bracale ${ }^{2}$, Nicola Longo ${ }^{2}$, Alessandro Palmieri ${ }^{2}$, \\ Ferdinando Fusco $^{2}$, Paolo Verze ${ }^{2}$, Gianluigi Califano ${ }^{2}$, Felice Crocetto ${ }^{2}$, Ciro Imbimbo ${ }^{2}$, \\ Vincenzo Mirone ${ }^{2}$, Vittorio Imperatore ${ }^{2}$, Massimiliano Creta ${ }^{2}$ \\ ${ }^{1}$ Madonna del Buon Consiglio, "Fatebenefratelli" Hospital, Naples; \\ ${ }^{2}$ Università degli Studi di Napoli "Federico II", Naples.
}

\begin{abstract}
Summary
Background: Bladder cancer is the eleventh most commonly diagnosed cancer worldwide. The recurrence rate of this cancer can be very high, up to $45 \%$. Photodynamic diagnosis (PDD) is more sensitive than standard procedures for the detection of malignant tumours. The aim of the study was to evaluate oncological outcomes in white light TURB (WL-TURB) and hexaminolevuninate blue light TURB (Hal-TURB).

Patients and methods: This was a retrospective longitudinal single-center study. In the period between January 2016 and October 2016 WL-TURB was the only therapeutic option available. From November 2016 until April 2017 all TURBs were fluorescence-guided (Hal-TURB). Kaplan-Meier curves have been used to estimate recurrence free survival rates. Results: One hundred and eleven patients underwent HalTURB and 137 underwent WL-TURB. Recurrence rate after 12 months was $19.8 \%$ (22 out of 111 patients) and $37.2 \%$ (51 out of 137 patients) in HAL-group and WL-group respectively $(p<0.01)$. The recurrence-free period was longer in HAL-group rather than WL-group (8.9 months vs 7.3 months, $p<0.05)$. Moreover, the recurrence rate during the first 6 months was $3.7 \%$ in patients who underwent HAL-TURB and $16 \%$ in those who received WL-TURB $(p<0.01)$.

Conclusion: The results of the study show that recurrence-free survival was longer in patients undergoing HAL-TURB compared to the patients who received standard WL-TURB.
\end{abstract}

KEY WORDS: Bladder cancer; Hexaminolevulinate; TURB; PDD; Fluorescence cystoscopy.

Submitted 3 June 2019; Accepted 19 July 2019

\section{INTRODUCTION}

Bladder cancer is the eleventh most commonly diagnosed cancer worldwide, with the highest incidence among men (1). The recurrence rate of this cancer at the first follow-up evaluation can be very high, up to $45 \%$ in patients with multiple tumours at the first diagnosis (2). Many studies suggest that early second transurethral resection of bladder tumor (re-TURB) improves staging and reduces the recurrence as well as progression rates in high-risk bladder cancer patients (3). In fact, considering the stochastic nature of the technique, a re-TURB performed 2-6 weeks after the first TURB may find residual tumour in up to $76 \%$ of patients (4). One of the reasons for the high recurrence risk of non-muscle invasive bladder cancer (NMIBC) is likely to be the persistence of residual lesions following initial TURB (5). A key goal in the treatment of NMIBC is the successful identification and removal of cancerous tumors to prevent either recurrence and progression of the disease in order to improve cancer-free and overall survival.

Photodynamic diagnosis (PDD) is performed using violet light after intravesical instillation of 5-aminolaevulinic acid (ALA) or hexaminolaevulinic acid (HAL). It has been confirmed that fluorescence-guided biopsy and resection are more sensitive than conventional procedures for the detection of malignant tumours, particularly for CIS (6). Moreover hexaminolevulinate-induced fluorescence cystoscopy, by improving the detection of bladder cancer, leads to a more complete resection and significantly better disease-free survival (7).

The aim of our study was to analyze the use of hexaminolaevulinate (HAL: Hexvix ${ }^{\circledR}$, Photocure, Norway) during TURB in naive patients and compare it to white light TURB (WL-TURB) in terms of recurrence rate within 12 months after TURB

\section{Patients AND methods}

This is a retrospective longitudinal single-center study. Naive patients with a suspicion of $\mathrm{Ta} / \mathrm{T} 1$ bladder tumour had been recruited from the urology outpatient clinic. The suspicion of bladder tumour had been based on positive urine cytology and flexible cystoscopy performed in the outpatient department by two qualified urologists. Exclusion criteria were previous diagnosis of bladder or upper urinary tract cancer, history of chronic specific or 
aspecific bladder cystitis, known allergy to HAL, presence of porphyria. In the period between January 2016 and October 2016 WL-TURB was the only therapeutic option available. From November 2016 until March 2017 all TURBs were fluorescence-guided (HAL-TURB).

The HAL solution was instilled into the bladder by a Nelaton catheter and was to be retained for at least $1 \mathrm{~h}$. Blue light induction was obtained with D-light C system by Karl Storz. At a first instance bladder inspection had been carried out under white light source, and the TURB had been performed under white light. Subsequently the bladder had been inspected under blue light to identify residual neoplastic tissue at the resection sites or additional tumours that had been missed during white light inspection.

WL TURB was performed using 1588 Aim Camera system (Stryker, San Jose, CA) instead. None of the patients received one-shot chemotherapy after TURB.

The histopathological evaluation and staging were performed in accordance with the TNM 2009 classification. Patients were treated and followed-up according to the European Association of Urology guidelines (6). All patients received the first cystoscopy at three months. If negative, the cystoscopy was repeated every 3 months in high-risk and intermediate-risk patients, while in low-risk patients it was repeated 9 months after.

A recurrence was defined as macroscopic tumour with the histopathological confirmation. Adverse events were recorded at each follow-up visit. All data have been recorded and analyzed with SPSS v. 25 (IBM Corp., Armonk, NY, USA). Recurrence free survival rates were estimated according to the Kaplan-Meier method, and differences were compared by a log-rank test.

\section{RESULTS}

The number of patients who underwent HAL-TURB for a suspicion of bladder cancer was 111, whilst 137 patients underwent WL-TURB. Only 17 patients were lost at fol-

Table 1.

Demographical and clinical characteristics.

\begin{tabular}{|c|c|c|c|c|c|}
\hline & & & & & p \\
\hline \multirow[t]{2}{*}{$\overline{\text { Age }}$} & & Hal-TURB (mean) & 111 & 61.68 & \multirow[t]{2}{*}{0.463} \\
\hline & & WL-TURB (mean) & 137 & 60.7 & \\
\hline \multirow[t]{2}{*}{ Lesion size (cm) } & & Hal-TURB (mean) & 111 & 2.194 & \multirow[t]{2}{*}{0.122} \\
\hline & & WL-TURB (mean) & 137 & 1.996 & \\
\hline \multirow[t]{4}{*}{$\overline{\text { Sex }}$} & & Hal-TURB (n) & 76 & $45.20 \%$ & \multirow[t]{4}{*}{0.826} \\
\hline & & WL-TURB (n) & 92 & $54.80 \%$ & \\
\hline & Women & Hal-TURB (n) & 35 & $43.80 \%$ & \\
\hline & & WL-TURB (n) & 45 & $56.30 \%$ & \\
\hline \multirow[t]{2}{*}{ Smokers } & & Hal-TURB (n) & 72 & $29.80 \%$ & \multirow[t]{2}{*}{0.124} \\
\hline & & WL-TURB (n) & 106 & $43.80 \%$ & \\
\hline \multirow[t]{2}{*}{ Positive cytology } & & Hal-TURB (n) & 19 & $7.70 \%$ & \multirow[t]{2}{*}{0.817} \\
\hline & & WL-TURB (n) & 25 & $10.10 \%$ & \\
\hline \multirow[t]{2}{*}{ Positive ultrasound } & & Hal-TURB (n) & 95 & $38.30 \%$ & \multirow[t]{2}{*}{0.108} \\
\hline & & WL-TURB (n) & 126 & $50.80 \%$ & \\
\hline \multirow[t]{2}{*}{ Positive cystoscopy } & & Hal-TURB (n) & 99 & $39.90 \%$ & \multirow[t]{2}{*}{0.233} \\
\hline & & WL-TURB (n) & 128 & $51.60 \%$ & \\
\hline
\end{tabular}

Table 2.

Hystology of the patients.

\begin{tabular}{|c|c|c|c|c|c|}
\hline & & & $\begin{array}{r}\text { Type } \\
\text { Hal-TURB }\end{array}$ & $\begin{array}{l}\text { f TURB } \\
\text { WL-TURB }\end{array}$ & Total \\
\hline \multirow[t]{5}{*}{ Hystology } & $\begin{array}{l}\text { Urothelial } \\
\text { carcinoma }\end{array}$ & \begin{tabular}{|l|} 
Count \\
$\%$ in Hystology \\
$\%$ in Type of TURB
\end{tabular} & $\begin{array}{c}80 \\
40.6 \% \\
72.1 \%\end{array}$ & $\begin{array}{c}117 \\
59.4 \% \\
85.4 \%\end{array}$ & $\begin{array}{c}197 \\
100.0 \% \\
79.4 \%\end{array}$ \\
\hline & Other tumours & $\begin{array}{l}\text { Count } \\
\text { \% in Hystology } \\
\% \text { in Type of TURB }\end{array}$ & $\begin{array}{c}11 \\
61.1 \% \\
9.9 \%\end{array}$ & $\begin{array}{c}7 \\
38.9 \% \\
5.1 \%\end{array}$ & $\begin{array}{c}18 \\
100.0 \% \\
7.3 \%\end{array}$ \\
\hline & $\overline{C I S}$ & \begin{tabular}{|l|} 
Count \\
$\%$ in Hystology \\
$\%$ in Type of TURB
\end{tabular} & $\begin{array}{c}5 \\
55.6 \% \\
4.5 \%\end{array}$ & $\begin{array}{c}4 \\
44.4 \% \\
2.9 \%\end{array}$ & $\begin{array}{c}9 \\
100.0 \% \\
3.6 \%\end{array}$ \\
\hline & $\begin{array}{l}\text { Urothelial carcinoma } \\
+ \text { CIS }\end{array}$ & $\begin{array}{l}\text { Count } \\
\% \text { in Hystology } \\
\% \text { in Type of TURB }\end{array}$ & $\begin{array}{c}9 \\
64.3 \% \\
8.1 \% \\
\end{array}$ & $\begin{array}{c}5 \\
35.7 \% \\
3.6 \% \\
\end{array}$ & $\begin{array}{c}14 \\
100.0 \% \\
5.6 \%\end{array}$ \\
\hline & No cancer & \begin{tabular}{|l|} 
Count \\
$\%$ in Hystology \\
$\%$ in Type of TURB
\end{tabular} & $\begin{array}{c}6 \\
60.0 \% \\
5.4 \%\end{array}$ & $\begin{array}{c}4 \\
40.0 \% \\
2.9 \%\end{array}$ & $\begin{array}{c}10 \\
100.0 \% \\
4.0 \%\end{array}$ \\
\hline Total & & \begin{tabular}{|l|} 
Count \\
\% in Hystology \\
$\%$ in Type of TURB
\end{tabular} & $\begin{array}{c}111 \\
44.8 \% \\
100.0 \%\end{array}$ & $\begin{array}{c}137 \\
55.2 \% \\
100.0 \%\end{array}$ & $\begin{array}{c}248 \\
100.0 \% \\
100.0 \%\end{array}$ \\
\hline
\end{tabular}

Table 3.

Chemotherapy/Immunotherapy after TURB.

\begin{tabular}{|c|c|c|c|c|c|}
\hline \multirow{3}{*}{$\begin{array}{l}\text { Chemotherapy/ } \\
\text { Immunotherapy after TURB }\end{array}$} & \multirow[b]{2}{*}{ MMC } & & \multicolumn{2}{|c|}{$\begin{array}{c}\text { Type of TURB } \\
\text { Hal-TURB WL-TURB }\end{array}$} & \begin{tabular}{|c|} 
Total \\
102 \\
\end{tabular} \\
\hline & & $\begin{array}{l}\text { Count } \\
\% \text { in Chemotherapy/ } \\
\text { Immunotherapy } \\
\text { after TURB } \\
\% \text { in Type of TURB }\end{array}$ & $\begin{array}{l}37.3 \% \\
55.9 \%\end{array}$ & $\begin{array}{l}62.7 \% \\
66.7 \%\end{array}$ & $\begin{array}{r}100.0 \% \\
62.2 \%\end{array}$ \\
\hline & $B C G$ & $\begin{array}{l}\text { Count } \\
\% \text { in Chemotherapy/ } \\
\text { Immunotherapy } \\
\text { after TURB } \\
\% \text { in Type of TURB }\end{array}$ & $\begin{array}{l}48.4 \% \\
44.1 \%\end{array}$ & $\begin{array}{l}51.6 \% \\
33.3 \%\end{array}$ & $\begin{array}{l}100.0 \% \\
37.8 \%\end{array}$ \\
\hline Total & & $\begin{array}{l}\text { Count } \\
\% \text { in Chemotherapy/ } \\
\text { Immunotherapy } \\
\text { after TURB } \\
\% \text { in Type of TURB }\end{array}$ & $\begin{array}{c}41.5 \% \\
100.0 \%\end{array}$ & $\begin{array}{c}58.5 \% \\
100.0 \%\end{array}$ & $\begin{array}{l}100.0 \% \\
100.0 \%\end{array}$ \\
\hline
\end{tabular}

low-up and were not included in statistical analysis (11 in HAL-TURB group and 6 in WL-TURB group). All TURBs were performed by 2 experienced surgeons.

Demographical and clinical characteristics of the two populations were summarized in Table 1. The populations were homogeneous. Mean age was 61.7 years (range 39-91) and 60.7 (range 39-81) in HAL-TURB group and WL-TURB group respectively $(\mathrm{p}=0.463)$. Of 248 patients with suspicion of bladder cancer 197 had a urothelial carcinoma, 14 concomitant CIS and urothelial carcinoma, 9 only CIS, 18 other tumors and 10 had no tumor (Table 2). Only ten patients were diagnosed with $\mathrm{T} 2$ or more invasive disease, however 38 patients underwent a cystectomy. No significant differences were found among the populations of the two groups in terms of 
Figure 1.

Kaplan-Meier curves on RFS.

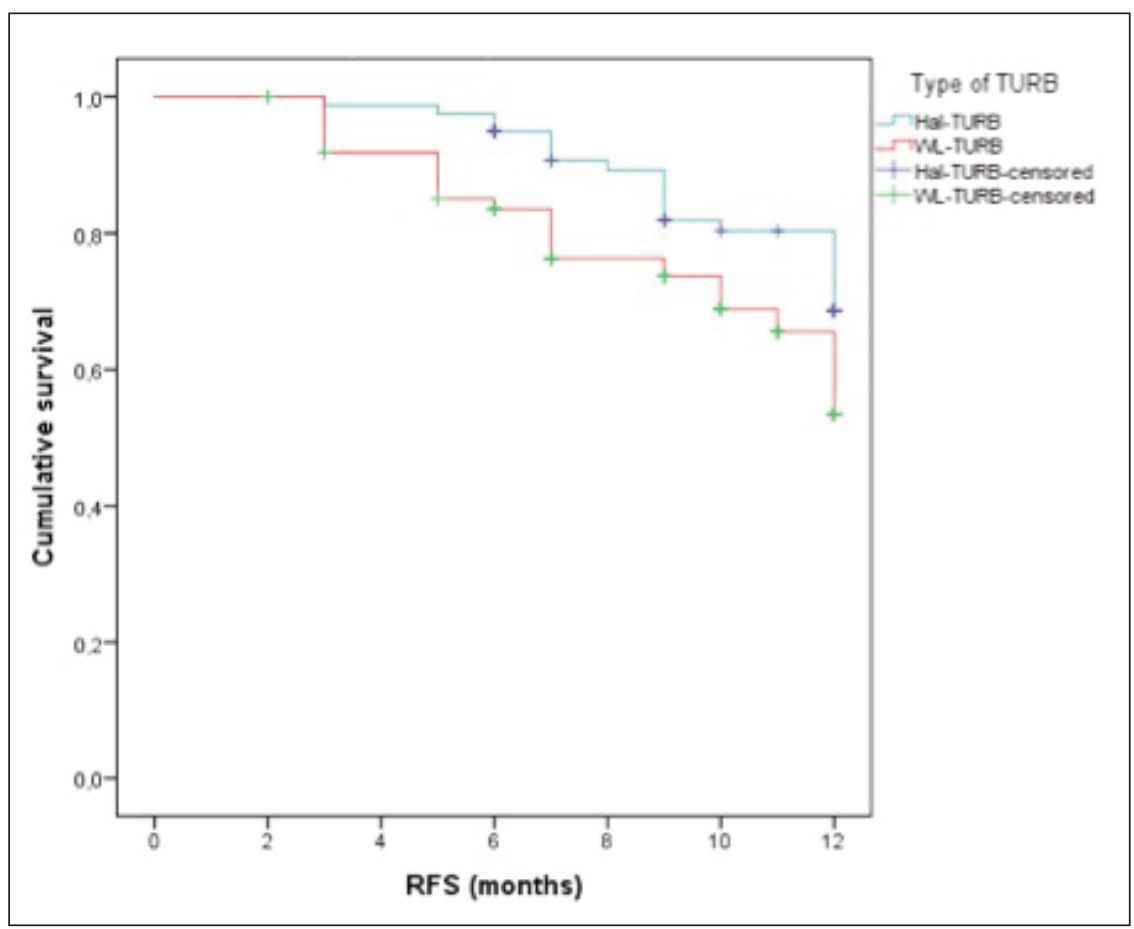

patients treated with HAL- vs. WLbased TURB (11). At the present time there are no long-term results on disease progression and overall survival, however it is desirable that these variables will decrease. Meanwhile the use of HAL-TURB leads to a reduction of further hospitalizations which in turn reduces hospital costs (12).

In our study we compared data of two different approaches to naïve patients with suspicion of bladder cancer. Our results show that recurrence-free period was longer in patients undergoing HAL-TURB rather than patients who received the standard WL-TURB.

Interestingly the recurrence rate during the first 6 months was hugely reduced in HAL-group than in WL-group (3.6\% vs 16\% respectively). A reasonable explanation might be better bladder cancer visualization which results in a more precise and complete initial resection. Therefore in our study we lay the foundation for a future

patients' characteristics, smoking habits, lesion size. Furthermore, no difference was detected between the percentages of patients undergoing chemotherapy or immunotherapy after TURB (Table 3). None of the patients received one-shot chemotherapy after TURB.

Recurrence rate after 12 months was 19.8\% (22 out of 111 patients) and $37.2 \%$ (51 out of 137 patients) in HAL-group and WL-group respectively $(p<0.01)$ (Figure 1). The recurrence-free period was longer in HAL-group rather than WL-group (8.9 months vs 7.3 months, $\mathrm{p}<0.05)$. In addition to that, recurrence rate during the first 6 months was 3.7\% in patients who underwent HAL-TURB and $16 \%$ in those who received WL-TURB $(\mathrm{p}<0.01)$.

No adverse events after the administration of HAL were recorded in the group who received the instillation.

\section{Discussion}

Nowadays the use of Hexvix on naive patients with bladder cancer suspicion is not advisable according to EAU guidelines (6).

A German multicenter study has confirmed that in patients undergoing TURB the use of HAL has improved by $6.8 \%$ the detection of cancerous lesions in comparison to the standard WL-TURB (8). In addition to that, a recent meta-analysis has confirmed the effectiuveness of HAL-TURB in reducing recurrence rate, however further studies have been claimed to reach a change in the clinical management of the disease (9). As shown in the literature it is also possible to evaluate a risk model for prediction of bladder cancer recurrence (10).

In another systematic review and meta-analysis the rate of cancerous progression was significantly lower in stratification of the risk based on the use of violet light after intravesical instillation of 5-aminolaevulinic acid during the initial TURB.

The future goal will be the preoperative identification of a sub-group of patients who can benefit from the HalTURB at the first resection.

\section{Clinical practice points}

Many studies have pointed the benefit of performing fluorescence-guided TURB in terms of recurrence rate and progression rate. In our study we have demonstrated that in patients undergoing Hal-TURB the recurrence free survival was dramatically reduced in the first 6 months. This might be helpful in the search of pre-operative selection of the patients who will definitely benefit from this treatment.

\section{REFERENCES}

1. Ferlay J, Soerjomataram I, Dikshit R, et al. Cancer incidence and mortality worldwide: sources, methods and major patterns in GLOBOCAN2012. Int J Cancer. 2015; 136:E359-86.

2. Witjes JA, Kiemeney LA, Oosterhof GO, Debruyne FM. Prognostic factors in superficial bladder cancer. A review. Eur Urol. 1992; 21:89-97.

3. DobruchJ, Borówka A, Herr HW. Clinical value of transurethral second resection of bladder tumor: systematic review. Urology. 2014; 84:881-5.

4. Creta M, Mirone V, Di Meo S, et al. Endoscopic Spatulation of the intramural ureter: a technique to prevent stenosis of the ureterovesical junction in patients undergoing resection of the ureteral orifice. $J$ Endourol. 2016; 30:913-7. 
5. Witjes JA, Babjuk M, Gontero P, et al. Clinical and cost effectiveness of hexaminolevulinate-guided blue-light cystoscopy: evidence review and updated expert recommendations. Eur Urol. 2014; 66:863-71

6. Babjuk M, Burger M, Compérat E, et al. Non-muscle invasive bladder cancer. European Association of Urology guidelines 2019.

7. Stenzl A, Burger M, Fradet Y, et al. Hexaminolevulinate guided fluorescence cystoscopy reduces recurrence in patients with nonmuscle invasive bladder cancer. J Urol. 2010; 184:1907-13.

8. Bach T, Bastian PJ, Blana A, et al. Optimised photodynamic diagnosis for transurethral resection of the bladder (TURB) in German clinical practice: results of the noninterventional study OPTIC III. World J Urol. 2017; 35:737-744.

9. Lee JY, Cho KS, Kang DH, et al. A network meta-analysis of therapeutic outcomes after new image technology-assisted transurethral resection for non-muscle invasive bladder cancer: 5-aminolaevulinic acid fluorescence vs hexylaminolevulinate fluorescence vs narrow band imaging. BMC Cancer. 2015; 15:566.

10. Vartolomei MD, Ferro M, Cantiello F, et al. Validation of Neutrophil-to-lymphocyte Ratio in a Multi-institutional Cohort of Patients With T1G3 Non-muscle-invasive Bladder Cancer. Clin Genitourin Cancer. 2018; 16:445-452.

11. Gakis G, Fahmy O. Systematic review and meta-analysis on the impact of hexaminolevulinate - versus white-light guided transurethral bladder tumor resection on progression in non-muscle invasive bladder cancer. Bladder Cancer. 2016; 2:293-300.

12. Klaassen Z, Li K, Kassouf W, et al. Contemporary cost-consequence analysis of blue light cystoscopy with hexaminolevulinate in non-muscle-invasive bladder cancer. Can Urol Assoc J. 2017; 11:173-181.

\section{Correspondence}

Marco Capece, MD

drmarcocapece@gmail.com

Roberto Buonopane, MD

robertobuonopane@libero.it

Sergio Di Meo, MD

sedime72@yahoo.com

Madonna del Buon Consiglio, "Fatebenefratelli" Hospital, Naples

Lorenzo Spirito

lorenzospirito@msn.com

Roberto La Rocca, MD

robertolarocca87@gmail.com

Luigi Napolitano, MD

nluigi89@libero.it

Maurizio Sodo, MD

maurizio.sodo@unina.it

Umberto Bracale, $M D$

umberto.bracale@unina.it

Nicola Longo, MD

nicolalongo20@yahoo.it

Alessandro Palmieri, MD

info@alessandropalmieri.it

Ferdinando Fusco, MD

ferdinando.fusco2@libero.it

Paolo Verze, MD

pverze@gmail.com

Gianluigi Califano, MD

gianl.califano2@gmail.com

Felice Crocetto , MD

felice.crocetto@gmail.com

Ciro Imbimbo, MD

cimbimbo@unina.it

Vincenzo Mirone, MD

mirone@unina.it

Vittorio Imperatore, $\mathrm{MD}$

v.imperatore1@gmail.com

Massimiliano Creta, MD

max.creta@gmail.com

Università degli Studi di Napoli "Federico II", Naples 